\title{
FEATURES
}

\section{Tuning into bird songs for clues to autism}

\author{
BY SARAH DEWEERDT
}

8 SEPTEMBER 2021

\section{Listen to this story: \\ https://www.spectrumnews.org/wp- content/uploads/2021/09/audio-22b81adf-60d3-4ae1-aae6-304075eebc40-encodings.mp3}

The communication and language difficulties seen in people with autism are challenging to study in animals, for obvious reasons. But scientists have seen parallels between human speech and the songs of some birds. Young male zebra finches (Taeniopygia guttata) learn to sing by listening to and imitating adults, much as children learn to speak. In both songbirds and young children, this learning takes place during a 'critical period' early in development and involves analogous neural circuits. Because of these similarities, songbirds such as zebra finches have become important models for the study of language learning in autism.

Over the past several decades, scientists have developed detailed knowledge of song circuits in birds, says Todd Roberts, associate professor of neuroscience at the University of Texas Southwestern Medical Center in Dallas. This background "gives us a really good foundation" for evaluating the function of autism-linked genes that might play a role in language, he says:

Scientists know just where to look in songbird brains for the effects of particular genes.

Many human brain regions governing speech show similar gene-expression profiles to those of song-related regions in birds. About a decade ago, researchers began to document how some autism-linked genes, such as CNTNAP2, are expressed at high levels in birdsong brain regions, suggesting that these genes play a role in the birds' ability to sing. They have since tracked how the expression of certain autism-linked genes changes during the process of song learning. When young male zebra finches sing, the level of an autism-linked protein called reelin increases in a song-related region called Area X. So does the amount of the activated form of a protein called DAB1, which is also linked to autism. So these genes may be involved not just in singing in birds, but in learning to sing - and perhaps in language-learning in people, too.

In the past five years, researchers have disrupted the expression of various autism-linked genes in 


\section{Spectrum | Autism Research News}

https://www.spectrumnews.org

zebra finch brains to evaluate the genes' roles in song learning. They have found that turning down production of CNTNAP2 in key song-learning areas of young male zebra finch brains impairs the birds' ability to learn songs from their fathers. They have suppressed expression of FOXP1 or FOXP2, autism-linked genes involved in language in people, in the birds' basal ganglia and found that doing so also impedes song learning. And a study published earlier this year suggested that dampening production of FOXP1 in a song region called HVC prevents young birds from learning new songs, although they can still practice and perfect songs they already know, hinting at a role for this gene in a specific aspect of the song-learning process.

Birdsong is not a perfect analog of language. A zebra finch's song is a single repeated sequence, simpler than the rich tapestry of human speech. "We can recombine these sounds to have many different meanings attached, whereas with the bird the meaning is really just: 'Hey, l'd like to be your mate,"' says Caitlin Aamodt, a postdoctoral researcher working with Eric Courchesne and Nathan Lewis at the University of California, San Diego.

But the similarities are strong enough that songbirds could help researchers understand language difficulties in autism and provide clues to improving language learning in autistic individuals. The birds might even provide a platform for testing treatments designed to bolster language skills. "One of the ultimate goals would be to understand at what stages of development you need to intervene by, and how strong or long-lasting those interventions need to be," Roberts says.

Cite this article: https://doi.org/10.53053/BCC09981 